\title{
Quality of care for the elderly: pressure injury risk as a marking condition
}

\author{
Qualidade da atenção aos idosos: risco de lesão por pressão como condição marcadora
}

Viviani Camboin Meireles ${ }^{1}$, Vanessa Denardi Antoniassi Baldissera ${ }^{1}$

Objective: to analyze the quality of care provided in primary health care to frail elderly individuals at risk of pressure injury. Methods: multiple case study. Sixteen elderly and their family caregivers and ten health professionals participated in the study. Results: among nonconformities were the non-realization of screening of the degree of frailty and multidimensional evaluation of the elderly; absence of pressure injury risk assessment; scarcity of material and human resources; lack of support for family caregivers; delay in meeting the needs of equipment for mobilization; lack of knowledge on the part of professionals and caregivers. Conclusion: the study led to the conclusion that the marker is a tool that evaluates the course of care and, in the case of frail elderly people with risk for pressure injury, and fragilities range from professional knowledge to systematic practices that include the care network.

Descriptors: Quality of Health Care; Primary Health Care; Health of the Elderly; Pressure Ulcer.

Objetivo: analisar a qualidade dos cuidados prestados na atenção primária à saúde aos idosos frágeis com risco para lesão por pressão. Métodos: estudo de caso múltiplo. Participaram da pesquisa 16 idosos e seu cuidador familiar e dez profissionais de saúde. Resultados: entre as não conformidades estão a inexistência do rastreamento do grau de fragilidade e avaliação multidimensional dos idosos; a ausência de avaliação de risco de lesão por pressão; a escassez de recursos materiais, humanos; a falta de apoio aos cuidadores familiares; a demora no atendimento das necessidades de dispositivos para mobilização; o deficit de conhecimento por parte dos profissionais e cuidadores. Conclusão: o estudo concluiu que a condição marcadora é uma ferramenta que avalia o percurso do cuidado e, em se tratando do idoso frágil com risco para lesão por pressão, as fragilidades vão desde o conhecimento profissional até práticas sistemáticas que incluam a rede de cuidados.

Descritores: Qualidade da Assistência à Saúde; Atenção Primária à Saúde; Saúde do Idoso; Lesão por Pressão.

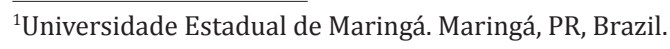

Corresponding author: Viviani Camboin Meireles

Universidade Estadual de Maringá, bloco 01, CEP: 87020900. Maringá, PR, Brazil. E-mail: vivianimeireles@gmail.com 


\section{Introduction}

A pressure injury is localized damage to the skin and/or underlying soft tissue usually over a bony prominence or related to a medical or other device ${ }^{(1)}$. This type of injury can not only cause pain and discomfort, but also increase morbidity and mortality, especially among the elderly. It results in a costly treatment and increased workload of the health team and caregivers. Thus, this type of injury deserves attention for its prevention. In Brazil, data on pressure injury at the home environment indicate that there is between $41.2 \%$ and $59.0 \%$ risk for development, with prevalence between 8 and $23.0 \%{ }^{(2)}$.

Much has been discussed about the prevention of pressure injury in services of high and medium complexity. Care should also be offered in primary health care, under the responsibility of Family Health Teams, based on guidelines already established for home care $^{(3)}$. It is important also to remember that the Pressure Ulcer Prevention Protocol ${ }^{(2)}$ provides recommendations to be applied to all individuals who are at risk of developing such injuries in different care settings, such as home.

The presence of a pressure injury is a negative indicator of the quality of the care provided, being considered internationally as an adverse event, and represents an important challenge for health care $^{(4)}$. Nurses are recommended to use the Braden scale for early identification of people at risk of pressure injury ${ }^{(5)}$, which is essential for a systematic approach to prevention and appropriate care.

In this study, the identification of the risk of pressure injury, considered here as a marker of quality of the care provided, was used as a basis to list the care measures provided to frail elderly at risk for this event, allowing to evaluate multiple aspects of care beyond the pressure injury, referred to as nonconformities ${ }^{(6)}$. The tracing method, also called tracking method or the screening of process failures, uses a typical activity of the health system to evaluate the care given to a certain marking condition ${ }^{(7)}$. The method also examines the troubleshooting, appropriate use of complementary tests, access to medicines and to other levels of health care.

The marking condition to be tracked must be chosen among those to which there are already well established programs whose standards of care have been approved by health professionals ${ }^{(7)}$ who have in-depth scientific knowledge on risk, prevention, therapeutic factors and appropriate scales for evaluation and classification.

Considering that the marking condition allows to analyze how the work processes and its relationship with service directives and quality of care are concretized in practice, this study was anchored in the following question: Is the care for frail elderly individuals at risk of pressure injury provided on primary health care in a qualified and safe manner? To answer this question, the research was developed with the objective of analyzing the quality of care provided in primary health care to frail elderly individuals at risk of pressure injury.-

\section{Methods}

A multiple case study ${ }^{(8)}$ that used the risk of pressure injury as a problem and marking condition to infer the quality and safety of care provided to frail elderly individuals at risk of pressure injury.-

Base on the identification of these elderly, the care process was mapped to allowing the definition of conformities and nonconformities that serve as parameters to infer quality and safety of care $\mathrm{e}^{(1-3,9)}$.

The study was conducted in a Basic Health Unit within the area of coverage of a family health team from a municipality of the north of the state of Paraná, Brazil. Five professionals of the family health team (two community workers, a nurse, a physician, and a nursing technician) and five nursing technicians who worked in basic health unit among the 14 eligible units participated in the study, as well as 16 elderly patients and their family caregivers among the 52 eligible elderly. The participants had to meet following 
inclusion criteria. In the case of the elderly, the inclusions criteria were: a) to be on the list of elderly people (over 60 years of age) registered in the Basic Health Unit; b) to have a family caregiver; c) to have been indicated by the Family Health Team as an elderly who needs family care; d) to have been classified as frail according to the Vulnerable Elders Survey-13 (VES-13) ${ }^{(10)}$; e) to have been classified as elderly person at risk of developing pressure injury assessed by a predictive scale $^{(5)}$. In the case of caregivers, the inclusion criteria were: to be the main family caregiver of an elderly participant of the study. And in the case of professionals, the criteria were: a) to be linked to the Basic Health Unit of reference of the Family Health Team or to be a member of it; b) to be a professional who assist the elderly (physician, nurse, social worker, nutritionist, community health agent, physiotherapist).

Data collection took place from February to September 2018 and was divided into two stages. The first stage was designed to characterize the eligible elderly and to select them to participate in the study, and the second stage consisted in the application of instruments to evaluate the quality of care. Three forms were applied in the first phase: 1) a form for the characterization of demographic data and ambulatory care sensitive conditions of the elderly, applied at the patient's home during home visits; 2) the VES-13 to the classification of frailty of the elderly, applied at the patient's home, composed of 13 items about age, self-perception of health, presence of physical limitations and disabilities, whose sum can range from zero to 10 , where a score of 7 points or more indicates frailty; 3 ) a risk assessment scale ${ }^{(5)}$ applied at the patient's home, consisting of six subscales - sensory perception, activity, mobility, friction and shear, moisture and nutrition.

Five of these subscales have scores ranging from 1 to 4 , except friction and shear, whose score varies from 1 to 3, which together result in an overall score ranging from 6 to 23 points. The risk of developing such injuries, according to the scale, is classified as follows: scores $\leq 12$ indicate very high risk; between 10 and 12 indicate high risk; 13 or 14 indicate moderate risk; between 15 and 18 indicate low risk; scores $\geq 19$ indicate no risk.

After assessing the frail elderly and those at risk of pressure injury, the risk of pressure injury was assumed as a marking condition ${ }^{(7)}$ of the quality of care that began to be mapped through the follow-up of the health care provided, the records of professional care regardless of whether it occurred at home or at the Basic Health Unit, and the survey of the knowledge and practices of professionals and family caregivers.

Then, the second stage of the research was started, consisting in the implementation of the following instruments and methods: 1) script of observations during the home visits by the multidisciplinary team including the identification of the patient, reason of the visit, members of the multidisciplinary team present in the visit, procedures and guidelines provided in the form of a checklist which allowed registering the conformities and non-conformities of the actions in relation to the standards and guidelines of quality and safety in the care for elderly patients at risk of pressure injury, their possible causes and consequences; 2) form for collection of data from notes in electronic records, with respect to consultations held on the Basic Health Unit, home care consultations, and guidelines given by the team, in the form of a checklist which allowed to note the compliance and non-compliance of actions carried out/registered in relation to the standards and guidelines of quality and safety in the management of pressure injury risk, their possible causes and consequences $\left.{ }^{(1-3,9)} ; 3\right)$ application of the Clinical-Functional Vulnerability Index-20 (IVCF20) for the multidimensional assessment ${ }^{(11)}$, which is a standardized instrument on line guide to the health of elderly people in the state of Paraná, Brazil, who are previously classified as frail or at risk of frailty according to the VES-13, and the result allows the evaluation of the major determinants of health of older persons through eight dimensions considered predictive of functional decline.

In this second phase, the knowledge and practices of professionals and family caregivers regarding 
pressure injuries were also surveyed through two other instruments: 4) an instrument to assess the caregiver's knowledge about pressure injuries ${ }^{(12)}$ applied at home to the caregivers who are family members of the frail elderly, after a previous appointment, composed of 35 questions about evaluation and classification, risk factors and prevention of pressure injury; 5) a questionnaire applied to professionals of the health team, composed of 63 questions on a Likert scale, seven referred to classification and 56 to risk factors and prevention of pressure injuries. This instrument was created and adapted by judges based on the recommendations of national and international guidelines $^{(1-2)}$.

An average of six visits per household of the elderly were performed in order to collect observations in home visits performed by the team, for the application of the IVCF-20, and application of the instrument for assessment of the knowledge of caregivers.

The data for characterization of participants were organized in a descriptive way and the analysis was based on absolute and relative frequencies. With regard to data from the analysis of the scripts of the home visits by professionals, the information collected in the electronic records was organized in a table from the classification into conformities and non-conformities ${ }^{(6)}$ with the quality and safety parameters ${ }^{(1-3,9)}$ and according to studies that corroborate the theme. A figure was drawn up with the mapping of care measures adopted for the elderly, comprising non-conformities, their possible causes and consequences involved. It should be clarified that non-conformities were defined as not complying with actions and procedures established in norms and guidelines to guarantee quality and safety, prevention of failures and risk of harm to the elderly, and that represent an opportunity to implement measures to improve the quality of care and safety for patients ${ }^{(1-3,9)}$.

As for the knowledge and practices of family caregivers and professionals, the data from the questionnaires were considered adequate when they had $\geq 90.0 \%$ of correct answers. For these instruments, the options "I agree" and "I partially agree" were considered to indicate true statement; the options "I disagree" and "I partially disagree" were considered to indicate false statements; and the option "I do not know" was considered as an error.

Pressure injury as a marker of quality was then discussed in the light of the literature on prevention of pressure injury ${ }^{(1-2)}$, patient safety at the home setting ${ }^{(3)}$ and health care guidelines for the elderly ${ }^{(9)}$. The present research is part of a larger project approved by the Ethics Committee of Research with Human Beings of the State University of Maringá under Opinion $n \div$ 875,081/2014 and Certificate of Presentation for Ethical Appreciation no 37457414,6,0000,0104.

\section{Results}

The elderly participants of this study were seven females $(43.8 \%)$ and nine $(56.2 \%)$ males. The majority of the women (five) were over the age of 80 years (85.7\%); among the men, four were aged between 70 and 79 years (44.4\%) and four over 80 (44.4\% $\%)$. All were retired, and retirement was the main source of income. As to movement, seven (43.7\%) participants used devices (walking stick or walker), five (31.3\%) were wheelchair users, and four (25.0\%) were bedridden.

In relation to the classification of pressure injury risk, two (12.5\%) had low risk, eight (50.0\%) had medium risk and six (37.5\%), high risk. During the study period, two elderly patients (12.5\%) developed pressure injuries. Both of them were bedridden and had been classified as being at high risk: one of them presented a lesion in the sacral region and the other in the sacral and calcaneal region, even after advice from professionals and from the institution regarding preventive measures. Two elderly patients already had a pressure injury in the sacral region identified in the first home visit.

As for the family caregivers, 14 (87.5\%) were females and two (12.5\%) were males. With regard to the kinship of the women who were caregivers of the 
elderly, ten $(71.4 \%)$ were daughters, three $(21.4 \%)$ wives, and one (7.1\%) sister. Among the male caregivers, the two were children of the elderly. Among the female caregivers, eight (57.2\%) were in the age group of 51 to 60 years, three $(21.4 \%)$ in the age group of 61 to 70 years, and three $(21.4 \%)$ were under 50 years of age. Among the men, the two were in the age group under 50 years.

The professionals who participated in the study were a physician, a nurse, six nursing technicians and two community health agents; one professional $(10.0 \%)$ was male and nine $(90.0 \%)$ were females. As for age, six (60.0\%) were aged between 31 and 40, three (30.0\%) from 41 to 50 , and one (10.0\%) between 20 and 30.

With respect to the knowledge and practices of family caregivers regarding the evaluation and classification of pressure injuries, in only one of the seven questions the participants demonstrated to have adequate knowledge. Regarding the risk factors and the factors for prevention of pressure injuries, the respondents presented adequate knowledge in only 11 of the 28 questions. The lowest number of correct answers were related to the time for changing the position of bedridden elderly or elderly in the seated position, in the chair; massage in bony prominences and reddish areas; use of water or air gloves in the calcaneous region; classification of injuries; use of water or air round; and risk factors such as friction and moisture.

Hygiene care was also mentioned as important for prevention and treatment of pressure injuries. The caregivers mentioned measures such as keeping the elderly person clean, frequent diaper changes, skin hydration, good nutrition and hydration, movement stimulation, and light pressure on the skin.

Family caregivers of the elderly who presented a history of pressure injuries expressed a feeling of lack of help from the Basic Health Unit and the professionals, thus indicating that they did not receive adequate material resources or home visits and guidelines. They reported having sought other professio- nals and complementary services of the Unified Health System to take care of dressings and physiotherapy.

It was seen that, among the nursing professionals participating in this study, the knowledge and practices were insufficient, and continuing education was non-existent. Data from the questionnaire and the form also pointed to this result. Regarding the seven statements about the classification of pressure injuries, only two $(28.6 \%)$ of the questions revealed adequate knowledge. They were particularly related to pressure injury stage 1 , in which the skin is intact, and injury in mucous membranes usually caused by medical devices. Data from the questionnaires showed that the professionals presented an adequate level of knowledge in only 22 (39.3\%) of the 56 items on risk factors and factors for prevention of pressure injuries.

The professionals mentioned outdated strategies and technologies for prevention of pressure injuries, such as the use of water-filled gloves, ring-shaped pillows, water mattresses, and massage in hyperemic bone prominences, as well as the use of the Braden scale for evaluation of pressure injury risk and the new nomenclature and classification defined as the responsibility of the nurse. Records of the stratification of the degree of frailty as a responsibility of community health agents or nursing technicians were not found for all the elderly living in the area of primary care coverage. The use of the IVCF-20, which should be applied to elderly patients who are classified as being at risk of frailty or as frail for referral to other levels of health care, if necessary, was not observed. However, the medical records showed that consultations for the elderly patients occurred sporadically, without systematization of care, and they were based on medicalization and renewal of prescriptions, which was often done by the family caregiver without the presence of the elderly patient.

The observations and annotations in the medical records showed that the process to access equipment such as wheelchairs and cushions is time consuming, bureaucratic and depends on the com- 
munication between the professionals and the scheduling availability with the reference physiotherapist (which is sometimes restricted).

In this context, there were non-conformities in thecases examined.Thefrail elderlywerenotsubmitted to risk assessment and multidimensional assessment to guarantee access to the health care networks, three Primary Care consultations, and request for exa- minations according to the municipal protocol. It was also possible to see the lack of infrastructure and material and human resources affecting the whole work process.

This compiled information allowed to list the non-conformities found, as not meeting the requirements pre-established in the literature and their possible causes and consequences based on the use of pressure injuries as a marker (Figure 1).

\begin{tabular}{|c|c|c|}
\hline Non-conformities & Possible related causes & Consequences \\
\hline $\begin{array}{l}\text { Absence of screening of the degree of frailty of } \\
\text { the elderly and application of the Instrument } \\
\text { for Assessment of Vulnerability for the Elderly } \\
\text { and the Clinical-Functional Vulnerability Index }\end{array}$ & $\begin{array}{l}\text { Reduced number of professionals for the } \\
\text { area of coverage }\end{array}$ & $\begin{array}{l}\text { Lack of longitudinal care and forwarding to } \\
\text { other levels of care }\end{array}$ \\
\hline $\begin{array}{l}\text { Delay in meeting the needs for devices (walking } \\
\text { sticks, wheelchairs, pressure relief cushions) }\end{array}$ & $\begin{array}{l}\text { Delay in evaluating and meeting the need } \\
\text { for devices }\end{array}$ & $\begin{array}{l}\text { Risk to the safety, autonomy and indepen- } \\
\text { dence of the elderly } \\
\text { Greater difficulty in managing care with safe- } \\
\text { ty }\end{array}$ \\
\hline $\begin{array}{l}\text { Lack of knowledge of family caregivers and } \\
\text { professionals about pressure injuries }\end{array}$ & $\begin{array}{l}\text { Insufficient continuing education and } \\
\text { health education actions }\end{array}$ & $\begin{array}{l}\text { Increased pressure injury risk to poor quality } \\
\text { of care }\end{array}$ \\
\hline $\begin{array}{l}\text { The work process of the team does not include } \\
\text { a systematic approach to identification of risks, } \\
\text { prevention, and treatment of pressure injuries }\end{array}$ & $\begin{array}{l}\text { Lack of standardization in the actions } \\
\text { related to pressure injuries }\end{array}$ & $\begin{array}{l}\text { Difficulty in directing the work and recording } \\
\text { the care measured adopted by the multipro- } \\
\text { fessional team }\end{array}$ \\
\hline
\end{tabular}

Figure 1 - Non-conformities in the care provided to frail elderly individuals at risk of pressure injury

\section{Discussion}

The study presents as a limitation the fact that data were collected in the area covered by one Family Health Team; thus, the reality here does not necessarily represent the reality of other services. Another limitation is the fact that the study was conducted on an area of coverage that has a population size of reference that is above the recommended for a health team ${ }^{(13)}$, which can be considered an atypical scenario for reliability of the analysis of the care process. It should be noted that there is a deficit of professionals in the Family Health Team, since at least four community health agents are recommended per team, as well as a population of 3,500 people ${ }^{(13)}$. However, the present team has only two community health agents, one nurse and one physician linked to one family health team and they meet the demand of a health area which has a population of approximately 8,000 people.

The initiative of the guide line of the state of Paraná( ${ }^{(9)}$ stands out as a model of care for the elderly. This initiative suggests the periodic risk assessment of elderly patients and the implementation of follow-up at the primary and secondary levels of care. In this context, elderly patients classified as frail have the right to schedule three annual consultations in primary 
care. This model would also enable timely interventions by health care points directed at areas affected or at risk of loss of global functionality.

This logic of care was not found in the present study. As these factors characterize a safe, quality care that meets the real needs of this population, it is necessary to invest in human resources aiming at full coverage, continuing education, standardization, and implementation of health care actions for the elderly. Furthermore, the results obtained in this study are in line with the literature regarding the organization of services, accessibility, and fragility of therapeutic bond relationships between users and health professionals as factors that may influence the longitudinality and safety of care ${ }^{(4,14)}$. In fact, the biological demand is what pushes users to seek the health care service, but the patients seek not only the resolution of the case but also expect the establishment of a relation of embracement and access to services ${ }^{(15)}$.

It was found that the acquisition of devices such as wheelchairs and cushions is a time consuming and bureaucratic process, with difficult access, delayed service, and low complementarity with other levels of care. Other studies converge with evidence that demonstrates rehabilitation services as a critical axis in the Brazilian health system ${ }^{(16)}$.

Regarding the knowledge of family caregivers, their knowledge about the classification of pressure injuries was not adequate. Although knowing the staging of pressure injuries is not the responsibility of caregivers, it is important that at least the first stage be recognized. This is the stage in which the skin is still intact, and a bleachable erythema is present. This recognition can make it possible intervene before the worsening of the injury. In addition, it is necessary that the caregiver know the risk factors and appropriate measures to prevent pressure injuries.

Regarding the knowledge of health professionals about the management of pressure injuries, this also fell short of the ideal, as found in other realities $^{(4,12,17-18)}$. It is essential that professionals use up-to-date knowledge and guiding principles to plan care, promote the quality and safety of care, and provide appropriate guidance to caregivers who will continue the treatment at the home setting.

Evidence regarding the prevention of pressure injuries points to the need to use a predictive scale for the identification of risk of pressure injury and periodic reassessment of all bedridden patients ${ }^{(1-3)}$. These recommendations are related to the systematization of care and reduction of unnecessary healthcare-related risks and damages to an acceptable minimum, that is, to do what is feasible in the light of current knowledge, and with the available resources and according to the context in which care is being provided ${ }^{(3,17)}$.

The shortcomings observed in this study and in others point out to the need for investment in programs of continuing education and health education. It is recognized that educational interventions consist of strategies that contribute to the gain and updating of knowledge to transform health practices ${ }^{(3-4,17-18)}$.

The contributions of this research to nursing consist in the use of the tracing method and marking condition to analyze the quality and safety of care for prevention of pressure injuries in frail elderly in primary health care; the non-conformities behave as indicators of the reformulation of care, where nurses and the nursing team are the main protagonists.

\section{Conclusion}

It was observed that the quality and safety of the process of care to the elderly are precarious and have fragilities in the following non-conformities: absence of screening of the degree of frailty and multidimensional evaluation of the elderly; absence of pressure injury risk assessment; scarcity of material and human resources; lack of support for family caregivers; delay in meeting the needs of equipment for mobilization; limited knowledge anchored in scientific evidence demonstrated by professionals and caregivers regarding the evaluation, management and prevention of pressure injuries.

The risk of developing pressure injury as a ma- 
rking condition has proved to be an important tool for mapping the quality and safety of care to frail elderly patients in primary health care.

\section{Acknowledgements}

To the Graduate Nursing Program of the Universidade Estadual de Maringá.

\section{Collaborations}

Meireles VC collaborated with the design, data collection, analysis and interpretation of the data and writing of the article. Baldissera VDA collaborated with the conception and design, interpretation of the data, and relevant critical review of intellectual content. All authors contributed to final approval of the version to be published.

\section{References}

1. Edsberg LE, Black JM, Goldberg M, McNichol L, Moore L, Sieggreen M. Revised national pressure ulcer advisor panel pressure injury stating system. J Wound Ostomy Continence Nurs. 2016; 43(6):585-97. doi: dx.doi.org/10.1097/ WON.0000000000000281

2. Ministério da Saúde (BR). Protocolo para prevenção de úlcera por pressão [Internet]. 2013 [citado $2018 \mathrm{dez}$ 12]. Disponível em: https:// www20.anvisa.gov.br/segurancadopaciente/ index.php/publicacoes/item/ulcera-por-pressao

3. Ministério da Saúde (BR). Secretaria de Atenção à saúde. Departamento de Atenção Hospitalar e de Urgência. Segurança do paciente no domicílio. Brasília: Ministério da Saúde; 2016.

4. Caldini LN, Araújo TM, Frota NM, Barros LM, Silva LA, Caetano JA. Evaluation of educational technology on pressure injury based on assistance quality indicators. Rev Rene. 2018; 19:e32695. doi: dx.doi.org/10.15253/2175-6783.20181932695

5. Paranhos WY, Santos VLCG. Avaliação do risco para úlceras de pressão por meio da Escala de Braden na língua portuguesa. Rev Esc Enferm USP [Internet]. 1999 [citado 2019 jan. 18];
33(Esp.):191-206. Disponível em: http://www. ee.usp.br/reeusp/upload/pdF/799.pdF

6. The Joint Commission. Topic library item: Facts about tracer methodology [Internet]. 2016 [cited Nov 20, 2018]. Avaliable from: https://www. jointcommission.org/facts_about_the_tracer_ methodology/

7. Kessner DM. Evaluación de la calidad de la salud por el método de los procesos trazadores. In: White KL. Investigaciones sobre servicios de salud: una antología. Washington DC: Organización Panamericana de la Salud; 1992. p.555-63.

8. Yin RK. Estudo de caso: planejamento e métodos. Porto Alegre. São Paulo: Bookman; 2015.

9. Secretaria de Estado da Saúde do Paraná. Superintendência de Atenção à Saúde. Linha guia da saúde do idoso [Internet]. 2017 [citado 2019 jan. 14]. Disponível em: http://www.saude.pr.gov. br/arquivos/File/linhaguia_idoso.pdf

10. Maia FOM, Duarte YAO, Secoli SR, Santos JLF, Lebrão ML. Cross-cultural adaptation of the Vulnerable Elders Survey-13 (VES-13): helping in the identification of vulnerable older people. Rev Esc Enferm USP. 2012; 46(Esp):116-22. doi: dx.doi. org/10.1590/S0080-62342012000700017

11. Moraes EM, Carmo JA, Moraes FL, Azevedo RS, Machado CJ, Montilla DER. Functional Vulnerability Index-20 (IVCF-20): rapid recognition of frail older adults. Rev Saúde Pública. 2016; 50:81. doi: dx.doi. org/10.1590/S1518-8787.2016050006963

12. Nogueira PC, Godoy S, Mendes IAC, Roza DL. Knowledge on pressure ulcer prevention among caregivers of spinal cord injury patients. Aquichan. 2015; 15(2):188-99. doi: dx.doi.org/10.5294/ aqui.2015.15.2.3

13. Malta DC, Santos MAS, Stopa SR, Vieira JEB, Melo EA, Reis AAC. Family Health Strategy Coverage in Brazil, according to the National Health Survey, 2013. Ciênc Saúde Coletiva. 2016; 21(2):327-38. doi: dx.doi.org/10.1590/141381232015212.23602015

14. Paula CC, Silva CB, Nazário EG, Ferreira $T$, Schimith MD Padoin SMM. Factors Interfering with the Atribute Longitudinalit in the Primary Health Care: an Integrative Review. Rev Bras 
Enferm. 2017; 70(1):199-208. doi: http://dx.doi. org/10.5216/ree.v17i4.31084

15. Palhoni AR, Penna CMM. Health care in the constitution of health needs for users of the family health strategy. Cienc Cuid Saúde 2017; 16(4). doi: http://dx.doi.org/10.4025/cienccuidsaude. v16i4.40371

16. Santos FC, Costa EA, Aleluia IRS, Pinto EPP. Situational diagnosis of physical rehabilitation in the SUS of Salvador-Ba. Rev Ciênc Méd Biol. 2018;
17(2). doi: http://dx.doi.org/10.9771/cmbio. v17i2.26318

17. Soares CF, Heidemann ITSB. Health promotion and prevention of pressure injury: expectations of primary health care nurses. Texto Contexto Enferm. 2018; 27(2):e1630016. doi: http://dx.doi. org/10.1590/0104-070720180001630016

18. Marques ADB, Branco JGO, Cavalcante RC, Brito MCC, Deus SRM, Luz MHBA. Knowledge of family health professionals about pressure ulcer. Rev Estima. 2017; 15(2):63-73. doi: dx.doi. org/10.5327/Z1806-3144201700020002 